\title{
Minimally invasive mitral valve repair: for every patient, for every surgeon or still a work in progress?
}

\author{
Antonio M. Calafiore ${ }^{1}$, Antonio Totaro ${ }^{1}$, Nicola Testa ${ }^{1}$, Michele Di Mauro $^{2}$ \\ ${ }^{1}$ Department of Cardiovascular Diseases, Gemelli Molise, Campobasso, Italy; ${ }^{2}$ Division of Cardiac Surgery, D’Annunzio University, Chieti, Italy \\ Correspondence to: Antonio M. Calafiore, MD. Department of Cardiovascular Diseases, Gemelli Molise, Largo Agostino Gemelli, 1, 86100, \\ Campobasso, Italy. Email: am.calafiore@gmail.com. \\ Provenance and Peer Review: This article was commissioned and reviewed by the Guest Section Editor Jinlin Wu (Department of Cardiovascular \\ Surgery, Fuwai Hospital, Peking Union Medical College, Beijing, China). \\ Comment on: Axtell AL, Moonsamy P, Dal-Bianco JP, et al. Minimally Invasive Nonresectional Mitral Valve Repair Can Be Performed With Excellent \\ Outcomes. Ann Thorac Surg 2020;109:437-44.
}

Submitted Jan 07, 2019. Accepted for publication Feb 07, 2020.

doi: $10.21037 /$ jtd.2020.02.39

View this article at: http://dx.doi.org/10.21037/jtd.2020.02.39

The history of minimally invasive (MI) cardiac surgery started with coronary artery bypass surgery (1), but the term "minimally invasive" was defined as "an intervention that does not require median sternotomy or the use of cardiopulmonary bypass". The subsequent application of the same concept to mitral valve (MV) surgery changed the meaning of MI, from "no sternotomy, no cardiopulmonary bypass" to "no full sternotomy". Partial sternotomy, in fact, has been and is still used and cardiopulmonary bypass, of course, is part of the procedure. In general MI became minimally access. But a sentence in the last paragraph of the paper from Calafiore et al. (1), written in 1996, sounds as a prophecy: "Future generation of cardiac surgeons, especially those in training, will have to become familiar with minimally invasive cardiac procedures, especially MICAB." The interest in MI coronary artery bypass is again increasing $(2,3)$ and MI valve surgery is continuously expanding. The trend in MIMV surgery has been studied by Paparella et al. (4) in a multicenter study. They found that the MI approach became more frequent from 2011 (27.5\%) to 2017 (71.7\%), with a similar early mortality in subjects paired by propensity score. Cardiopulmonary bypass time and cross-clamping time reduced progressively over time.

However, if the benefits of MIMV surgery in terms of reduced intensive care and in-hospital stay, reduced rate of atrial fibrillation, less transfusion rate, lower readmission rate are now clear (4-7), a more comprehensive analysis identifies a few weak points. Most of the cases are concentrated in a few Institutions, where the results are optimal (8). On the other side a low surgical volume is considered to affect the quality of the surgical results $(8,9)$, as low volume Centers concentrate most of the complications. An analysis of the trends in less invasive MV operation in US showed that $26 \%$ of the Centers performed at least one procedure per year, but the median was 3 (10). Some complications appeared to occur more in MIMV surgery, as bleeding $(9,10)$, aortic dissection $(11)$, stroke $(10,11)$, phrenic nerve palsy (11) and in a recent paper it has been reported that the ejection fraction was reduced in patients who underwent MIMV repair if compared with propensity matched pairs undergone median sternotomy (12). However, most of these complications are related to the most critical part of MIMV surgery: the learning curve. A study indicated that 75 to 125 procedures were necessary to master the technique and that to maintain the skill is necessary at least 1 case per week (13). Another study reported that the number of operations necessary to overcome the learning curve was 60 for MV replacement and 90 for MV repair (14). It is then clear that the limit to the expansion of the technique is not only to perform the surgery or to choose the patient, but also to maintain the necessary expertise, impossible in low volume Centers. As a consequence, a MI approach, even if used since long time (15) to correct both degenerative (4) and functional (16) mitral regurgitation (MR), still is not the procedure of choice for MV repair. 
Which is the contribution of the paper by Axtell et al. (17) to our knowledge? The Authors report optimal outcome after minimally MIMV repair as result of careful patient selection. Axtell et al. (17) performed a MI approach in more or less one third of their cases, excluding patients with a greater comorbidity burden, a previous median sternotomy, more than mild aortic insufficiency, peripheral vascular disease, $M V$ calcifications, and any associated procedures (with the exception of PFO closure and left appendage closure). Predicted mortality was very low (mean STS score $0.37 \%, 0.24-0.59$ ). The Authors selected very carefully the MV pathology as well, as most of the patients had posterior leaflet prolapse and in only 7 the anterior leaflet was prolapsing. Four patients needed isolated annuloplasty, whereas in all the remaining artificial chords were implanted. This is an example of how a strict control of all the variables brings to an extraordinary result: no early mortality and a 3 -year survival of $100 \%$ without any valverelated reoperation.

Echocardiographic results were good, but somehow confusing. In the abstract it is stated that "At 3 years, freedom from recurrent at least moderate mitral regurgitation was $100 \%$ ". This statement is coherent with what written at pag 8 "At 3 years, freedom from more than moderate recurrent mitral regurgitation was $100 \%$ ", even if the definition of failure of repair is different. But at pag 9 it is written that "At one year, $11 \%$ of patients had trace to mild MR and no patients had moderate or severe MR", in conflict with what reported in Table 4 where, out of the 35 patients who had an echocardiographic evaluation after 1 year from surgery, 1 had moderate MR. It is not clear why the Authors emphasized in the text the absence of any moderate or more residual MR even 3 years after surgery. Even a single patient with moderate MR after 1 year is still a good result, even if the control was performed in only $1 / 3$ of the patients. We do not know how many patients had an echocardiogram at 3 years (surely only a few), to support the statement that none had moderate or more residual MR, and why the Authors did not report this data in Table 4. A statement not supported by data casts shadows on a report that, per se, is a lesson of caution and of respect for the patient. Pursuing a philosophy of "zero all" (zero mortality, zero reoperations, zero MR return) is not important, but can be only misleading.

Nevertheless, this study shows how a careful selection of patients, in combination with an optimal surgical technique, can bring to excellent results. However, if MI surgery is not for all the patients, it is not as well for all the surgeons.
It is still a work in progress, to be widely adopted when results can be reasonably good without any risk increase for the patients. Under this aspect this paper can have the potential danger to demonstrate that MIMV repair is easy and can be done always with great results, pushing to forget that behind these outcomes there is a lot of work and study. The paper does not state why the report starts from January 2014, if that one was the date when the Authors thought that the learning curve was completed and which were the results before that date. Surgery was performed by a single surgeon, evidently very experienced in MV repair, who carefully chose patients for MIMV repair. Under this conditions results can be only outstanding, but cannot be reproduced except if all the steps are completed.

\section{Acknowledgments}

Funding: None.

\section{Footnote}

Conflicts of Interest: All authors have completed the ICMJE uniform disclosure form (available at http://dx.doi. org/10.21037/jtd.2020.02.39). MDM serves as an unpaid editorial board member of Fournal of Thoracic Disease from Dec 2018 to Nov 2020. The other authors have no conflicts of interest to declare.

Ethical Statement: The authors are accountable for all aspects of the work in ensuring that questions related to the accuracy or integrity of any part of the work are appropriately investigated and resolved.

Open Access Statement: This is an Open Access article distributed in accordance with the Creative Commons Attribution-NonCommercial-NoDerivs 4.0 International License (CC BY-NC-ND 4.0), which permits the noncommercial replication and distribution of the article with the strict proviso that no changes or edits are made and the original work is properly cited (including links to both the formal publication through the relevant DOI and the license). See: https://creativecommons.org/licenses/by-nc-nd/4.0/.

\section{References}

1. Calafiore AM, Angelini GD, Bergsland J, et al. Minimally invasive coronary artery bypass grafting. Ann Thorac Surg 1996;62:1545-8. 
2. Nambiar P, Kumar S, Mittal CM, et al. Minimally invasive coronary artery bypass grafting with bilateral internal thoracic arteries: Will this be the future? J Thorac Cardiovasc Surg 2018;155:190-7.

3. Guida GA, Guida GA, Bruno VD, et al. Left thoracotomy approach for off-pump coronary artery bypass grafting surgery: 15 years of experience in 2500 consecutive patients. Eur J Cardiothorac Surg 2020;57:271-6.

4. Paparella D, Fattouch K, Moscarelli M, et al. Current trends in mitral valve surgery: A multicenter national comparison between full-sternotomy and minimallyinvasive approach. Int J Cardiol 2020;306:147-51.

5. Sundermann SH, Sromicki J, Rodriguez Cetina Biefer H, et al. Mitral valve surgery: right lateral minithoracotomy or sternotomy? A systematic review and meta-analysis. J Thorac Cardiovasc Surg 2014;148:1989-95 e4.

6. Goldstone AB, Atluri P, Szeto WY, et al. Minimally invasive approach provides at least equivalent results for surgical correction of mitral regurgitation: a propensitymatched comparison. J Thorac Cardiovasc Surg 2013;145:748-56.

7. Grant SW, Hickey GL, Modi P, et al. Propensity-matched analysis of minimally invasive approach versus sternotomy for mitral valve surgery. Heart 2019;105:783-9.

8. Nishi H, Miyata H, Motomura N, et al. Which Patients Are Candidates for Minimally Invasive Mitral Valve Surgery?- Establishment of Risk Calculators Using National Clinical Database. Circ J 2019;83:1674-81.

9. Nishi H, Miyata H, Motomura N, et al. Propensitymatched analysis of minimally invasive mitral valve repair using a nationwide surgical database. Surg Today 2015;45:1144-52.

Cite this article as: Calafiore AM, Totaro A, Testa N, Di Mauro M. Minimally invasive mitral valve repair: for every patient, for every surgeon or still a work in progress? J Thorac Dis 2020;12(4):1621-1623. doi: 10.21037/jtd.2020.02.39
10. Gammie JS, Zhao Y, Peterson ED, et al. J. Maxwell Chamberlain Memorial Paper for adult cardiac surgery. Less-invasive mitral valve operations: trends and outcomes from the Society of Thoracic Surgeons Adult Cardiac Surgery Database. Ann Thorac Surg 2010;90:1401-8, 1410.e1; discussion 1408-10.

11. Cheng DC, Martin J, Lal A, et al. Minimally invasive versus conventional open mitral valve surgery: a metaanalysis and systematic review. Innovations (Phila) 2011;6:84-103.

12. Kawamoto N, Fukushima S, Shimahara Y, et al. Benefit and Risk of Minimally Invasive Mitral Valve Repair for Type II Dysfunction- Propensity Score-Matched Comparison. Circ J 2018;83:224-31.

13. Holzhey DM, Seeburger J, Misfeld M, et al. Learning minimally invasive mitral valve surgery: a cumulative sum sequential probability analysis of 3895 operations from a single high-volume center. Circulation 2013;128:483-91.

14. Vo AT, Nguyen DH, Van Hoang S, et al. Learning curve in minimally invasive mitral valve surgery: a single-center experience. J Cardiothorac Surg 2019;14:213.

15. Mohr FW, Falk V, Diegeler A, et al. Minimally invasive port-access mitral valve surgery. J Thorac Cardiovasc Surg 1998;115:567-74; discussion 574-6.

16. Girdauskas E, Pausch J, Harmel E, et al. Minimally invasive mitral valve repair for functional mitral regurgitation. Eur J Cardiothorac Surg 2019;55:117-i25.

17. Axtell AL, Moonsamy P, Dal-Bianco JP, et al. Minimally Invasive Nonresectional Mitral Valve Repair Can Be Performed With Excellent Outcomes. Ann Thorac Surg 2020;109:437-44. 